\title{
PERANCANGAN APLIKASI SISTEM INFORMASI MEDIS MENGGUNAKAN BARCODE BERBASIS DESKTOP DAN ANDROID
}

\author{
Ida Bagus Surya Paramarta ${ }^{1}$, Made Sudarma ${ }^{2}$, Ida Bagus Alit Swamardika ${ }^{3}$ \\ 1,2,3 Jurusan Teknik Elektro dan Komputer, Fakultas Teknik, Universitas Udayana \\ Email : suryaparamarta@gmail.com ${ }^{1}$, msudarma@unud.ac.id ${ }^{2}$, gusalit@unud.ac.id ${ }^{3}$
}

\begin{abstract}
Abstrak
Penelitian ini bertujuan untuk merancang aplikasi sistem informasi medis yang menggunakan barcode di perangkat desktop dan Android. Perancangan aplikasi menggunakan Visual Basic, bahasa pemrograman Java dan MySQL untuk sistem database. Dalam aplikasi menggunakan tipe barcode kode 3 dan 9. Proses pertukaran data antara dekstop dan Android menggunakan jaringan lokal untuk mempermudah distribusi data. Aplikasi Sistem Informasi medis menggunakan barcode berbasis desktop dan Android dibuat melalui beberapa tahapan yaitu perancangan sistem, pembuatan database, pembuatan barcode, pembacaan barcode dan pengembangan aplikasi baik di desktop dan Android. Hasil kerja aplikasi Sistem Informasi Medis menggunakan Barcode berbasis desktop dan Android yaitu dapat menampilkan informasi data pasien kepada dokter melalui scan barcode yang ditampilkan pada aplikasi desktop maupun Android serta dapat memperbarui informasi data pasien maupun dokter di Klinik Karya Prima.
\end{abstract}

Kata Kunci : Android, Barcode, Database, Sistem Informasi

\section{Abstract}

This research aims to design an applications of medical information system that uses barcode on desktop and Android device. Designing applications using Visual Basic, the Java programming language and MySQL for database system. In an application using the barcode type code 3 and 9. The process of data exchanged between device and database is done by using local networks to make distribution data easier. Application of medical information system using barcode-based desktop and Android created through several stages for designing system which is creation database system, barcode design, scanning barcode and development of the application of both in desktop and Android. The results of application medical information system use barcode based desktop and Android that is able to display information data of the patient to the doctor through the scan the barcode displayed on Android and desktop applications can update the information data of patients as well as doctors a Clinic Karya Prima.

Keywords: Android, Barcode, Database, Information System,

\section{PENDAHULUAN}

IImu pengetahuan dan teknologi berkembangan dengan pesat di dalam berbagai bidang. Salah satu bidang tersebut adalah tata kelola informasi medis. Klinik Karya Prima adalah klinik yang menyelenggarakan pelayanan medis dasar. Sistem pendataan pasien di Klinik Karya Prima belum terkomputasi. Rekam medis pasien masih menggunakan kartu tertulis (manual), pendataan pasien dicatat dalam buku besar, serta kartu pasien masih menggunakan kartu tertulis secara manual. Klinik Karya Prima selaku penyedia layanan kesehatan diharapkan dapat memberikan pelayanan yang mudah dan instan dalam melakuan pendaftaran ataupun informasi pasien. Karena proses pencatatan registrasi, rekam medis, dan pembuatan kartu pasien masih manual, akan menjadi penghambat pemberi layanan cepat. Kekurangan ini dapat diatasi dengan menggunakan sebuah aplikasi sistem pendataan.

Penelitian-penelitian terkait dengan pengembangan aplikasi desktop dan Android di bidang kesehatan telah banyak dilakukan. Penelitian [4] merupakan sistem administrasi dan pendaftaran pasien yang dikembangkan menggunakan pendekatan teknologi 
terintegrasi sistem pengolahan data. Prosedur adminsitrasi yang sederhana mudah dan cepat merupakan salah satu peningkatan pelayanan kepada pasien. Pada penelitian [5] adalah penelitian yang bertujuan agar sebuah toko dapat berkembang berdasarkan strategi dan pengelolaan yang baik. Berdasarkan observasi dan wawancara, adanya sistem informasi memengaruhi berbagai aspek termasuk aspek penjualan. Sistem informasi penjualan dirancang secara komputerisasi dengan barcode yang bertujuan agar lebih efisien dan keakuratan pada data penjualan.

Penelitian menggunakan teknologi barcode yang dikombinasikan dengan koneksi internet melalui server dan sentral komputerisasi digunakan untuk meningkatkan akurasi data administrasi medis di unit pelayanan kesehatan. Beberapa penelitian melaporkan keefektifan barcode dalam mencegah kesalahan dalam pemberian obat (medication error) dan kesalahan pemberian transfusi darah (mistransfusion) sehingga meningkatkan keselamatan pasien [6]. Penelitian yang dilakukaan oleh Tominanto yaitu jenis penelitian yang digunakan adalah penelitian deskriptif, yaitu peneliti membuat program komputerisasi pendaftaran pasien berbasis card electric di Rumah Sakit Medika Mulya Wonogiri yang dapat mempermudah serta mempercepat proses pelayanan dan mempermudah petugas dalam pembuatan laporan yang rapi dan akurat. Komputerisasi pendaftaran pasien akan membantu mempercepat dan menyediakan informasi yang dibutuhkan oleh manajemen Rumah Sakit Medika Mulya Wonogiri [7].

Berdasarkan penelitian-penelitian sebelumnya yang telah dibahas, maka dalam penelitian ini akan dikembangkan sebuah aplikasi yang bertujuan untuk mempermudah pendataan pasien dan pengelolaan resource yang terdapat pada sebuah klinik pemberi layanan kesehatan. Aplikasi yang akan dikembangkan ini akan dalam bentuk desktop untuk pengguna personal komputer yang sifatnya tidak bergerak dan aplikasi mobile untuk smartphone Android. Aplikasi ini nantinya dilengkapi dengan penggunaan barcode pada identitas pasien sehingga membantu pendataan dan mendapatkan informasi yang lebih cepat dan tepat.

\section{KAJIAN PUSTAKA 2.1 Barcode}

Barcode digunakan untuk menyimpan data yang spesifik. Penyimpanan data di dalam barcode dasarnya dengan penyusunan garis vertikal hitam dan putih dalam bentuk maupun ketebalan yang berbeda [1]. Untuk meningkatkan produktivitas dan mengurangi kesalahan maka barcode digunakan dalam proses bisnis. Terdapat beberapa jenis standar barcode untuk berbagai tujuan dan kebutuhan dalam penggunaanya. Setiap jenis simbologi (atau tipe barcode) adalah standar yang mendefinisikan data yang tersimpan pada simbol tercetak dan bagaimana perangkat pemindai barcode, membaca dan menerjemahkan simbol yang tercetak. Jenisjenis barcode tersebut ditunjukkan pada Gambar 1 [8].

\section{BAR CODE SYMBOLOGIES}

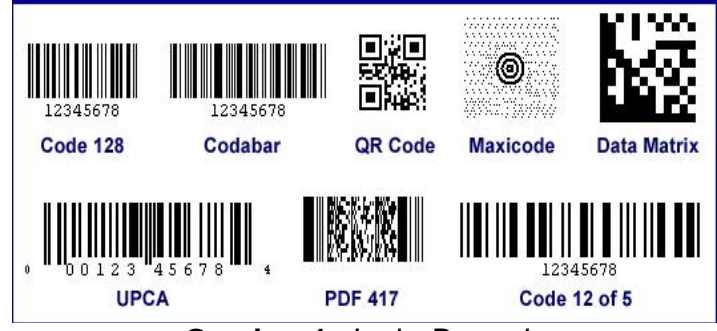

Gambar 1. Jenis Barcode

\subsection{Android}

Android merupakan sistem operasi untuk telepon seluler berbasis Linux sebagai kernelnya yang menyediakan platform terbuka (open source) bagi para pengembang untuk menciptakan maupun pengembangan aplikasi. Pada tahun 2003, Android didirikan oleh Andy Rubin, Rich Milner, Nick Sears dan Chris White. Android memiliki dua distributor, yaitu Google Mail Service (GMS) dan Open Handset Distributor (OHD). GMS adalah distributor Android yang mendapatkan dukungan penuh dari Google, sedangkan OHD adalah distibutor Android tanpa dukungan langsung dari Google [2]. Struktur framework Android terdiri dari kernel yang mencakup memory management, security setting, power management, dan beberapa driver hardware. Library yang digunakan adalah library Java. Program untuk mengatur fungsi- fungsi dasar smartphone adalah application framework. Secara garis besarnya, struktur framework Android ditunjukkan pada Gambar 2. 


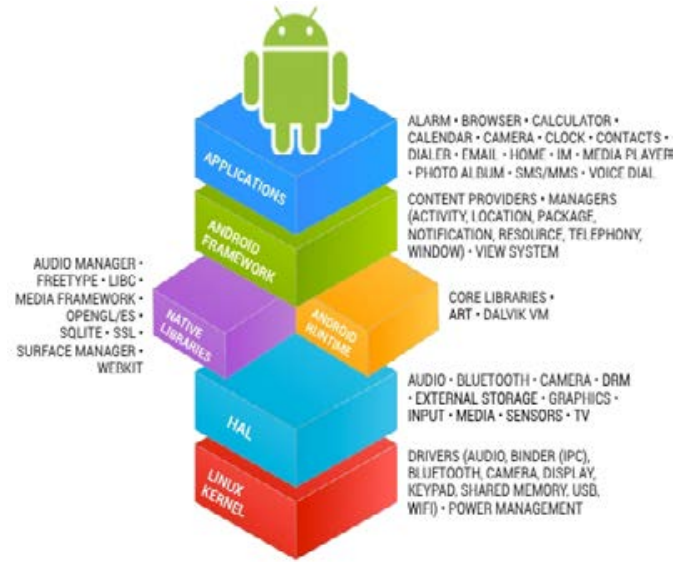

Gambar 2. Struktur Framework Android 2.3 Java

Java merupakan bahasa pemrograman berorientasi objek murni yang dibangun berdasarkan kekurangan dari bahasa pemograman sebelumnya yaitu $\mathrm{C}$ dan C++. Pada tahun 1991 James Gosling, developer dari Sun Microsystem menciptakan Java, dan diperkenalkan ke publik pada tahun 1995 [9]. Keunggulan Java adalah sifat keuniversalannya. Sistem operasi Linux, UNIX, Windows, Mac, dan lain-lain dapat menginplementasikan Java. Hasil kompilasi Java yang berupa bytecode dapat dijalankan di berbagai platform selama sistem memiliki JRE (Java Runtime Environment). Object Oriented Programming (OOP) merupakan karakteristik utama Java. OOP mempunyai ciri-ciri dan beberapa konsep penting, sebagai contoh object, class, method, enkapsulasi, inheritance, dan polimorfisme. Hal ini dapat memudahkan pengembang aplikasi untuk mendesain, membuat, mengembangkan, dan mengalokasi kesalahan sebuah program secara cepat, tepat, mudah, dan terorganisir.

\subsection{Database}

Database adalah suatu kumpulan data yang disimpan secara sistematis di dalam komputer yang dapat diolah menggunakan perangkat lunak untuk menghasilkan suatu informasi. Pendefinisian basis data meliputi spesifikasi berupa tipe data, struktur data, dan juga batasan-batasan data yang akan disimpan [10]. Proses memasukkan dan mengambil data ke dan dari media penyimpanan data memerlukan perangkat lunak yang disebut dengan sistem manajemen basis data atau Database Management System (DBMS). Menggunakan sistem perangkat lunak DBMS pengguna database dapat mengontrol, memelihara dan mengakses data secara praktis dan efisien [11].

\section{$2.5 \quad$ Visual Basic}

Visual basic adalah sebuah bahasa pemrograman yang berpusat pada object (Object Oriented Programming) digunakan dalam pembuatan aplikasi Windows yang berbasis Graphical User Interface (GUI) [11]. Dengan kode yang ditulis dalam bahasa $C$ Visual Basic dapat berinteraksi. Ada beberapa karakteristik obyek tidak dapat dilakukan oleh visual basic, misalnya inheritance (tidak bisa module) dan polymorphism yang secara terbatas bisa dilakukan dengan deklarasi class module dengan interface tertentu.

\section{METODE PENELITIAN}

Tahapan perancangan aplikasi sistem informasi medis menggunakan barcode berbasis desktop dan Android adalah sebagai berikut.

\subsection{Gambaran Umum Sistem}

Pembuatan aplikasi berbasis desktop menggunakan bahasa pemrograman Visual Basic, sedangkan dalam pembuatan aplikasi Android menggunakan bahasa pemrograman Java pada Android Studio. Mekanisme program aplikasi ini adalah sebagai berikut.

1. Admin dan operator melakukan login dengan aplikasi (desktop) serta mengisikan username dan password yang sudah didaftarkan atau aktif.

2. Apabila username masuk dengan id Admin/Operator maka dapat melihat dan mengelola sistem pendataan tersebut.

3. Apabila pendataan operator oleh Admin telah berhasil dilakukan, operator akan terdaftar dalam sistem tersebut dengan mendapatkan username dan password.

4. Admin dan operator yang terdaftar dapat melakukan pengelolaan data pasien, data penyakit, data riwayat penyakit, data dokter, dan data kartu kesehatan.

5. Apabila pendataan pasien oleh Admin/Operator telah berhasil, pasien akan terdaftar dalam sistem tersebut dan mendapatkan kartu pasien yang berisikan barcode sebagai Id.

6. Admin/Operator bertugas juga memasukkan master data dokter. Jika telah berhasil dimasukkan, dokter 
akan terdaftar dalam sistem tersebut dengan mendapatkan username dan password sebagai user dan memiliki hak akses pada aplikasi (Android) yang digunakan untuk melihat informasi pasien.

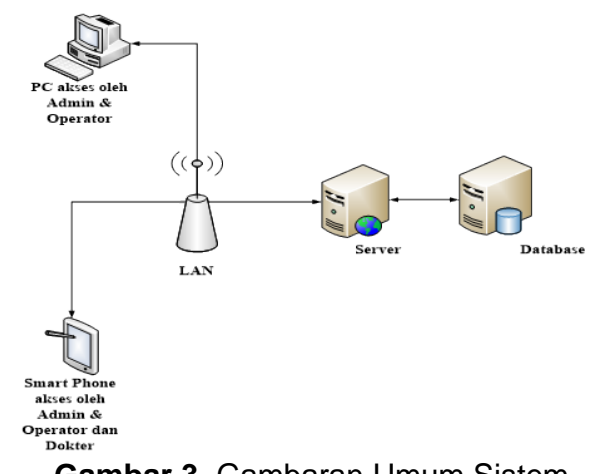

Gambar 3. Gambaran Umum Sistem

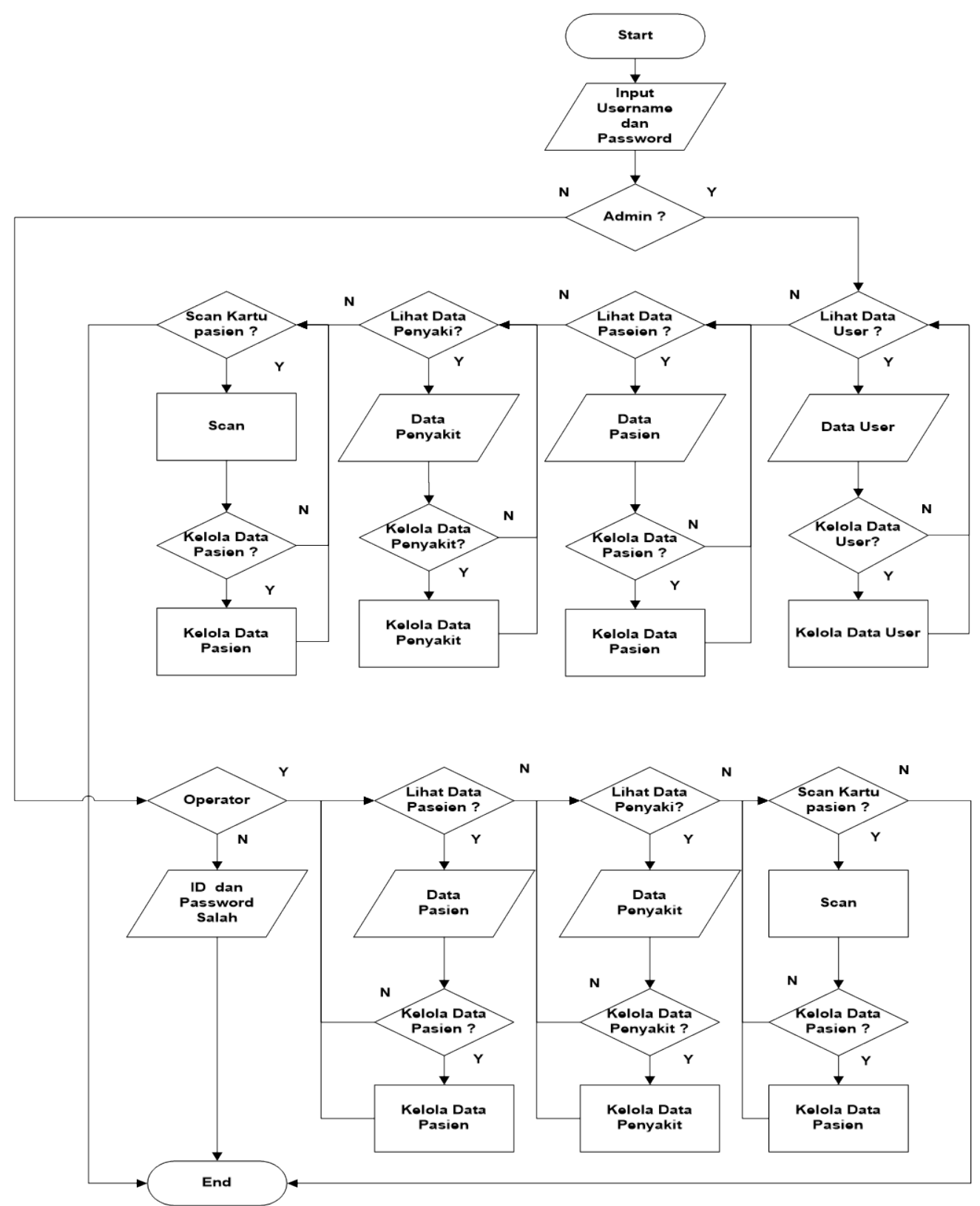

Gambar 4. Flowchart Sistem Desktop 


\subsection{Pembuatan Barcode}

Tipe barcode yang digunakan dalam penelitian ini adalah barcode tipe code 39. Kode tersebut dapat membaca seluruh huruf besar abjad dan karakter angka serta karakter tambahan seperti -, \$, /, +, \%, * dan spasi. Proses pembuatan barcode dengan langkahlangkah berikut.

1. Administrator melakukan proses convert barcode yang berisikan ID pasien pada masing-masing kartu.
2. Sistem mengubah angka-angka dari ID Pasien menjadi batangan barcode dalam bentuk gambar.

3. Gambar barcode yang sudah ada, dicetak ke kartu pasien. Setelah kartu diberikan barcode maka informasi terhadap pasien tersebut dapat diaskes ke dalam sistem sehingga kinerja dari Administrator menjadi lebih efisien

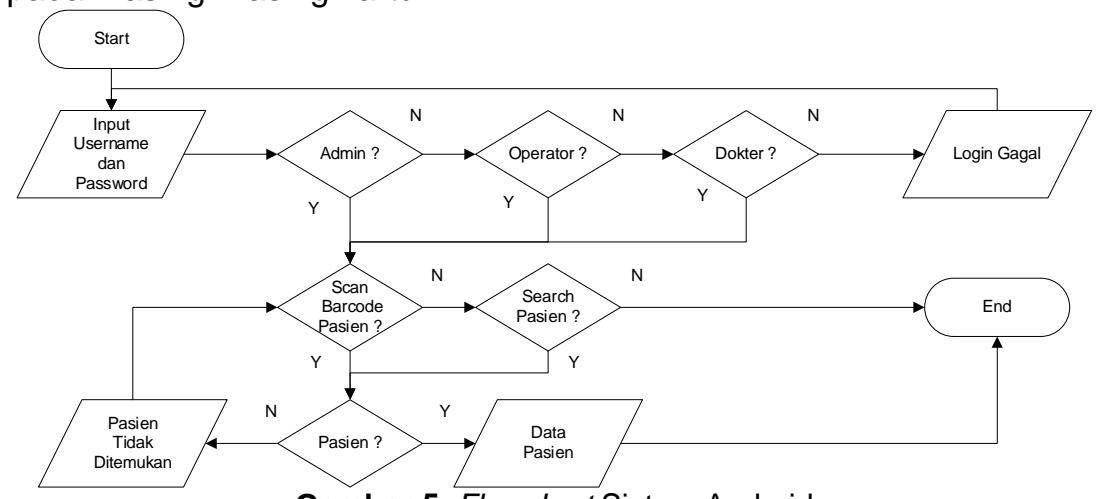

Gambar 5. Flowchart Sistem Android

\subsection{Flowchart Sistem Desktop}

Flowchart sistem desktop, Gambar 4, menjelaskan urutan alur dari sistem yang dibangun pada sistem informasi medis di desktop. Sistem desktop bertujuan untuk memproses semua data baik pasien dan dokter ke dalam database yang diinputkan oleh admin.

\subsection{Flowchart Sistem Android}

Workflow sistem android ditunjukkan pada Gambar 5, menjelaskan urutan alur dari sistem yang dibangun pada sistem informasi medis di Android. Sistem Android bertujuan untuk menampilkan data pasien dari database ke dalam aplikasi untuk user.

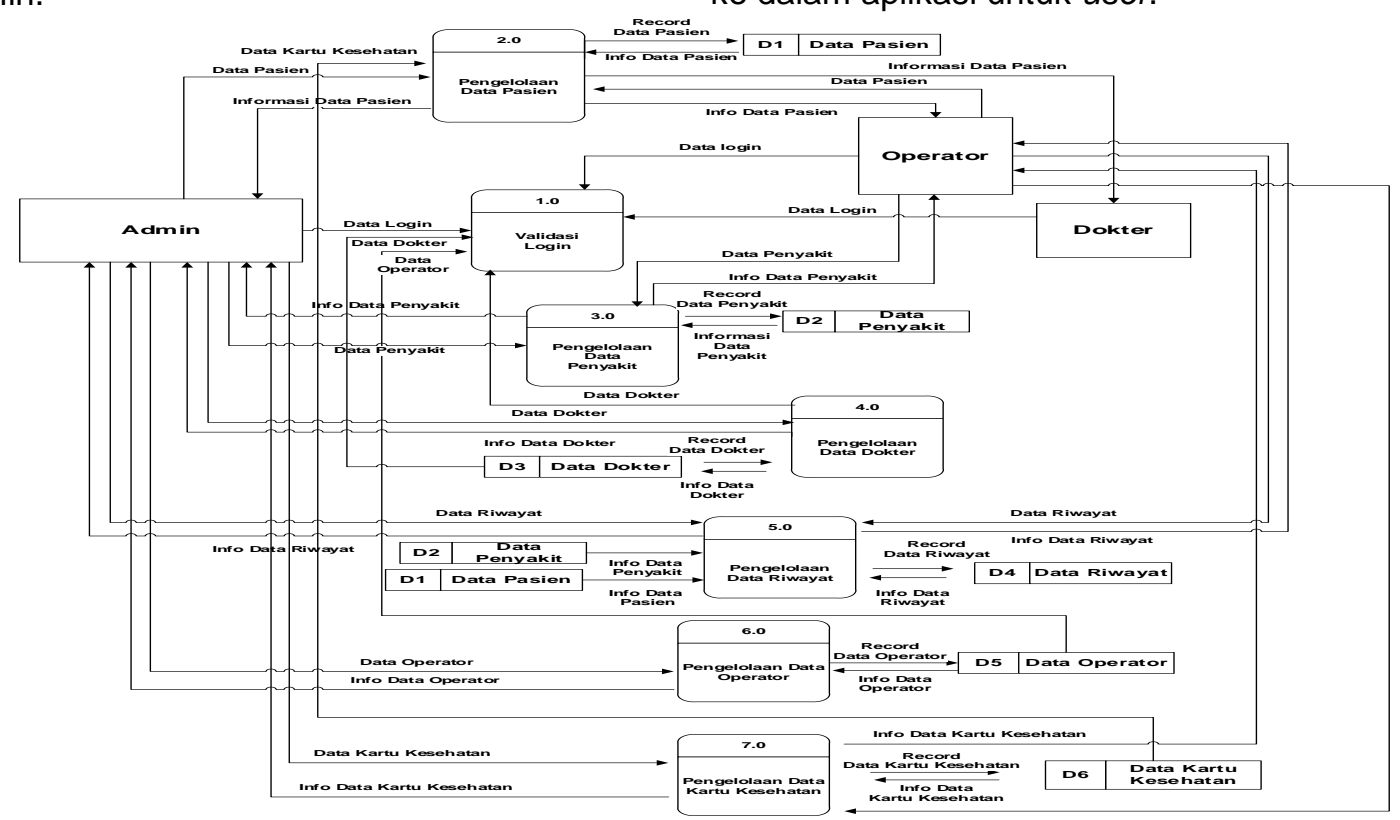

Gambar 6. DFD Level 0 Sistem Informasi Medis 


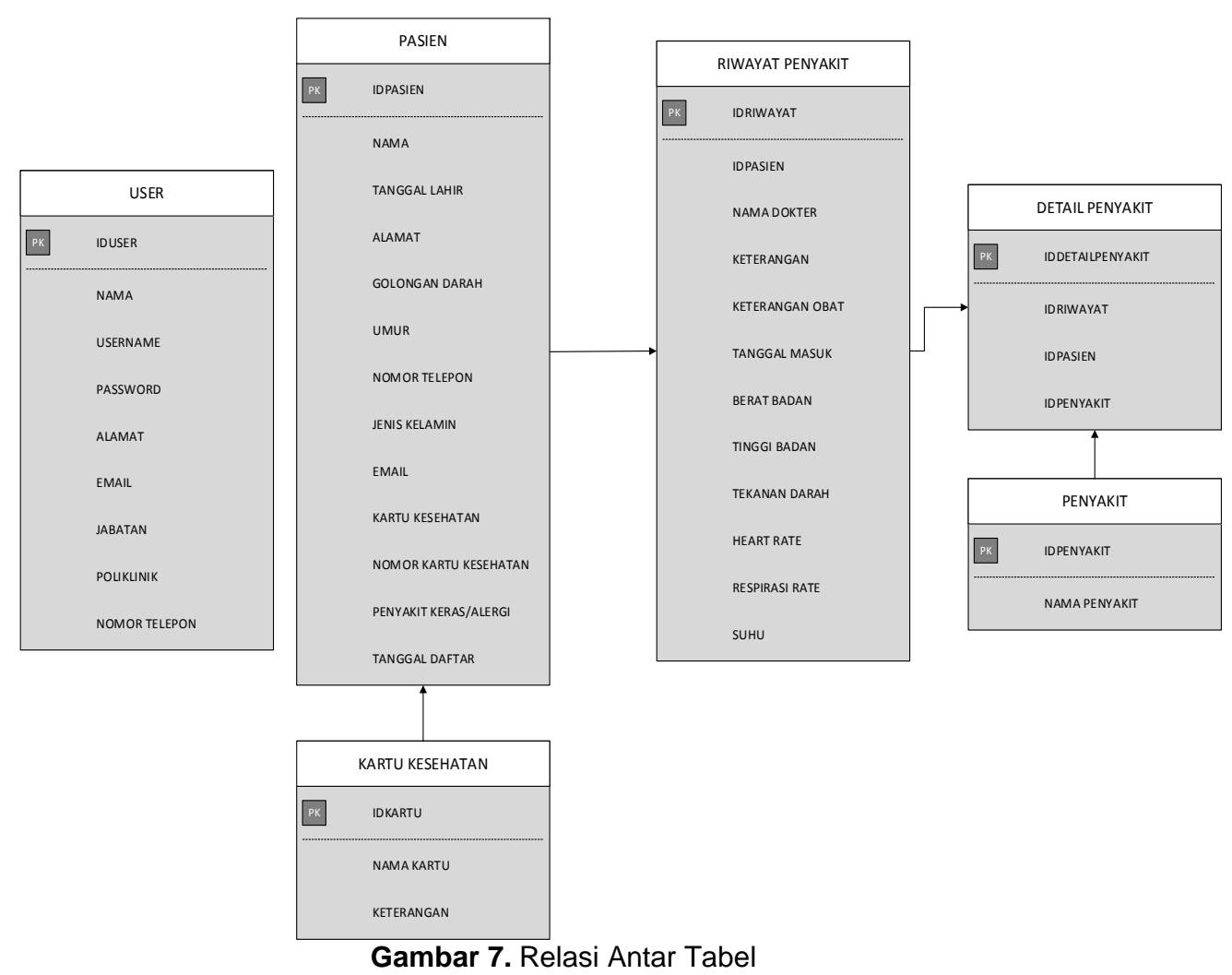

\subsection{Pemodelan Sistem}

DFD level 0, ditunjukkan pada Gambar 6 , berisikan tentang relasi atau hubungan antara entitas satu dengan entitas yang lain. Pada sistem ini didapat 7 proses DFD, yaitu validasi Login, Pengolahan data pasien, Pengolahan data penyakit, Pengolahan jadwal dokter, Pengolahan data Operator, Pengolahan data Riwayat, dan Pengolahan data Kartu Kesehatan.

\subsection{Perancangan Database}

Gambar 7 adalah gambar relasi antar tabel pada database sistem informasi medis. Dalam diagram tersebut terdapat relasi antara Tabel User, Pasien, Kartu Kesehatan, Riwayat Penyakit, Detail Penyakit. dan Penyakit.

\section{HASIL DAN PEMBAHASAN}

Hasil perancangan aplikasi sistem informasi medis menggunakan barcode berbasis desktop dan Android dapat dilihat sebagai berikut.

\subsection{Hasil Perancangan Aplikasi}

Dari penelitian yang telah dilakukan didapatkan hasil berupa aplikasi sistem informasi medis menggunakan barcode berbasis desktop dan Android. Aplikasi pada sisi dekstop yang dibangun pada penelitian ini menggunakan bahasa pemrograman Visual Basic sedangkan pada sisi aplikasi Android menggunakan bahasa pemrograman Java, serta untuk menyimpan data menggunakan database MySQL.

\subsection{Pembahasan Aplikasi}

Aplikasi sistem informasi medis ini didesain mempunyai role 3 user sesuai dengan jabatan yang dimiliki untuk melakukan pengolahan dan pencarian data. Pertama, user dengan jabatan Admin memiliki seluruh akses untuk mengelola data. Kedua, user sebagai Operator meiliki hak akses hampir sama dengan admin yang membedakannya adalah tidak dapat melakukan pengolahan data user. Ketiga, user sebagai Dokter hanya memiliki hak akses pada aplikasi android yang dapat digunakan untuk melihat data pasien dan riwayat penyakit yang diderita sebelumnya.

\subsubsection{Implementasi Aplikasi Berbasis Desktop \\ 1. Halaman Login}

Halaman Login, Gambar 8, merupakan halaman awal untuk pengguna masuk ke 
halaman menu utama sesuai hak akses yang dimiliki.

\section{Halaman Menu Utama}

Gambar 9 merupakan halaman menu utama. Halaman ini hanya dapat diakses oleh pengguna dengan hak akses sebagai admin dan operator. Halaman menu utama tersebut mencakup menu Scan Kartu Pasien, Data User, Data Pasien, Data Penyakit, Data Riwayat dan Data Kartu Kesehatan. Perbedaan hak akses operator dan admin adalah operator tidak dapat mengakses data user.

\section{Halaman Menu Scan Kartu}

Halaman Menu Scan Kartu Pasien pada Gambar 10 berfungsi untuk melihat data pasien yang sudah dibuat, mencakup biodata lengkap pasien seperti nama, tanggal lahir, alamat, email, nomer telepon, golongan darah, kartu kesehatan, penyakit keras atau alergi, jenis kelamin dan tanggal terdaftar dengan cara melakukan scanning menggunakan barcode scanner.

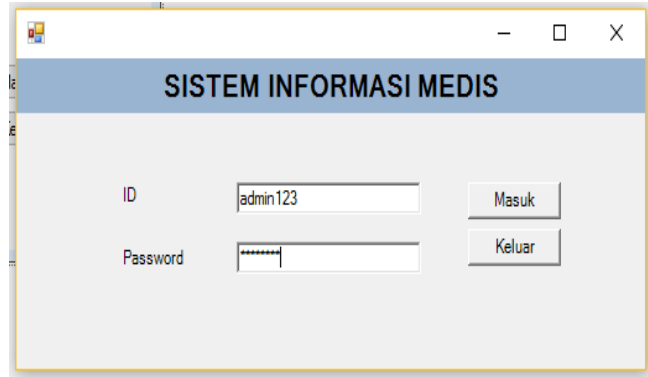

Gambar 8. Halaman Login Desktop

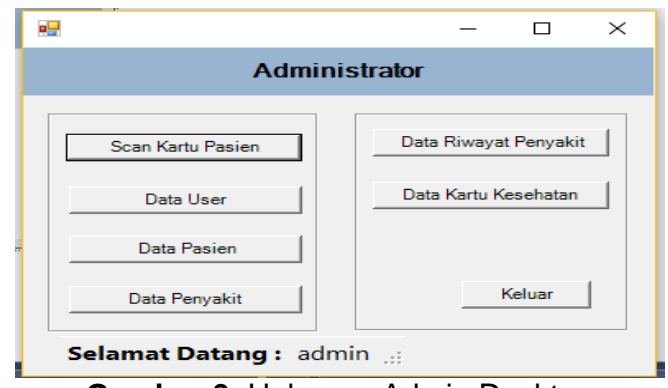

Gambar 9. Halaman Admin Desktop

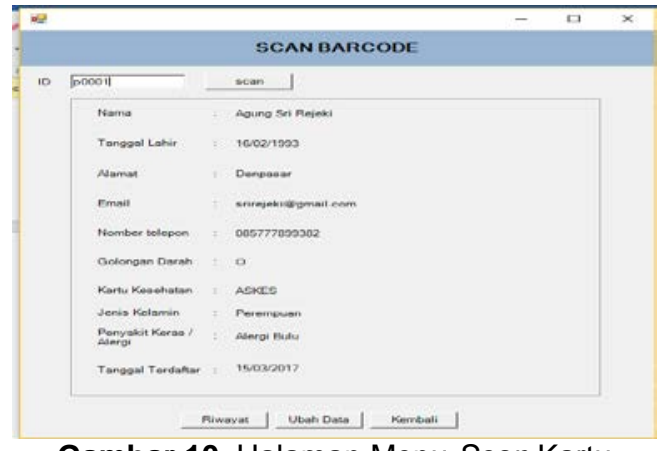

Gambar 10. Halaman Menu Scan Kartu

4. Halaman Menu Pengolahan Data

Halaman menu Pengeloahan data berfungsi untuk mengelola semua data seperti menambah data, mengubah data, dan menghapus data. Menu pengolahan data yang termasuk di dalamnya adalah Pengolahan Data User, Gambar 11, Pengolahan Data Pasien, Gambar 12, Pengolahan data Riwayat, Gambar 13, Pengolahan Data Penyakit ,Gambar 14, dan Pengolahan Data Kartu Kesehatan, Gambar 15.

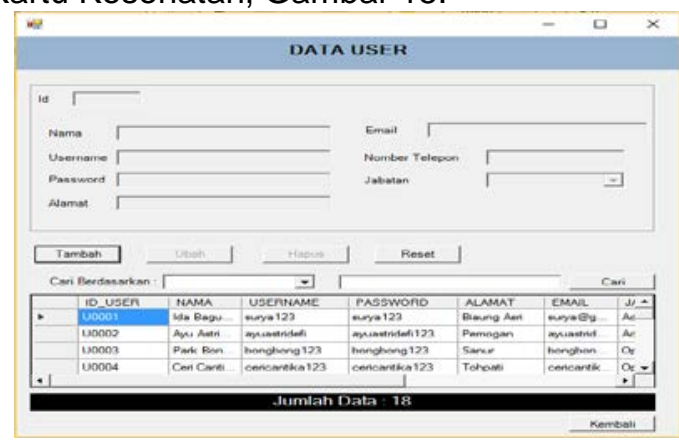

Gambar 11. Halaman Menu Pengolahan Data User

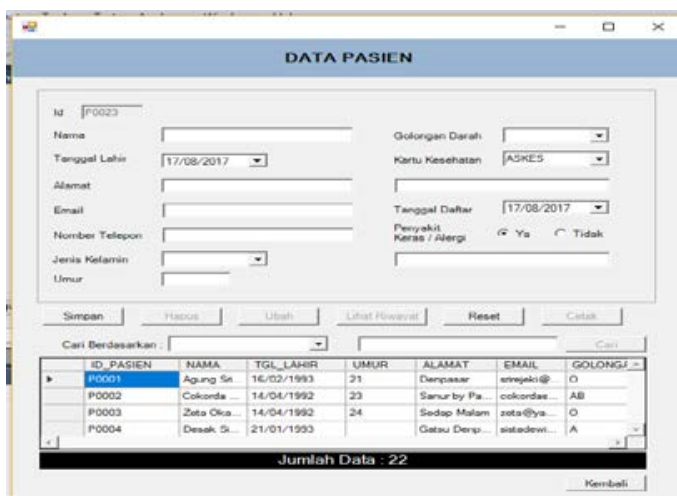

Gambar 12. Halaman Menu Pengolahan Data Pasien 

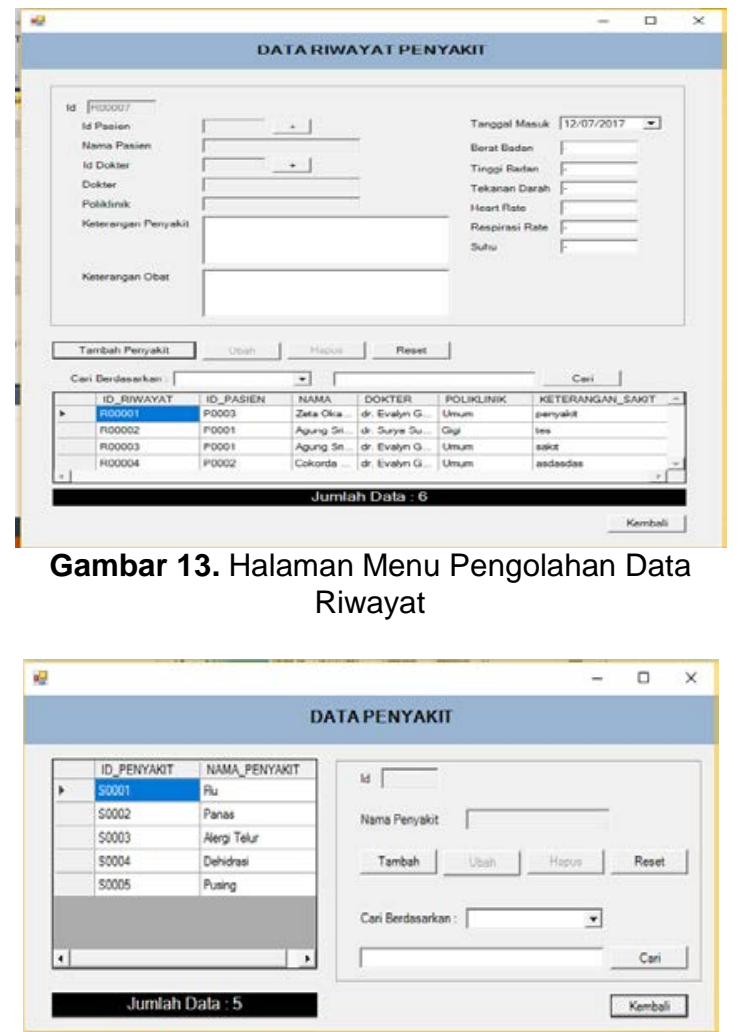

Gambar 14. Halaman Menu Pengolahan Data Penyakit

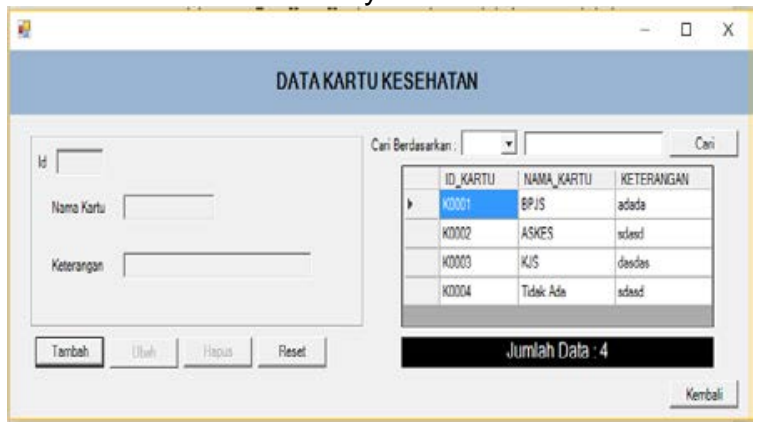

Gambar 15. Halaman Menu Pengolahan Data Kartu Kesehatan

\subsubsection{Implementasi Aplikasi Berbasis Android}

Berikut merupakan tampilan aplikasi sistem informasi medis menggunakan barcode berbasis Android.

1. Tampilan Login Android

Tampilan login Android pada Gambar 16 merupakan tampilan awal aplikasi, sebelum masuk ke dalam sistem informasi medis. User diharuskan untuk memasukkan username dan password yang telah didaftarkan terlebih dahulu oleh admin.

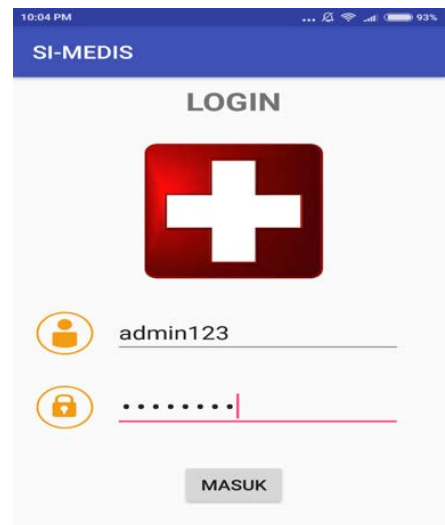

Gambar 16. Tampilan Login Android

2. Tampilan Menu Utama Android

Tampilan menu utama pada Gambar 17 berisikan menu sistem informasi medis yang dapat dipilih oleh user. Hak akses admin , operator dan dokter pada aplikasi berbasis Android memiliki fungsi yang sama untuk melihat data dari pasien, pembedanya hanya pada menu utama saat user login terdapat nama user dan jabatan user.

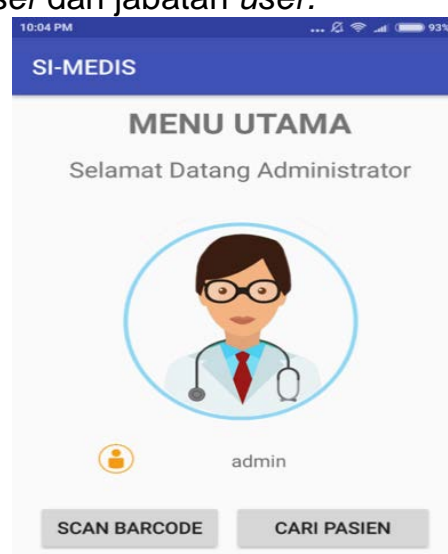

Gambar 17. Menu Utama Admin Android

3. Tampilan Menu Cari Pasien Android

Menu cari pasien pada Gambar 18 ini berfungsi untuk menampilkan data pasien pada list dengan memasukan nama pasien.

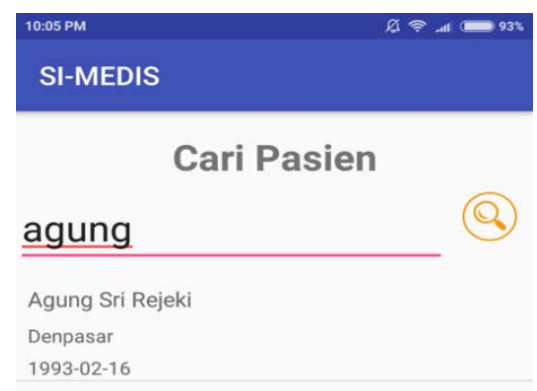




\section{Gambar 18. Menu Cari Pasien Android}

4. Tampilan Menu Data Pasien Android Menu data pasien pada Gambar 19 berisikan semua informasi yang ada pada pasien.

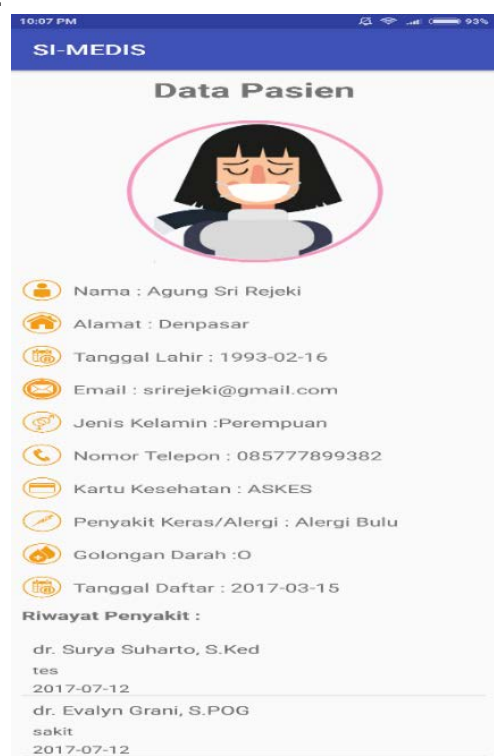

Gambar 19. Menu Data Pasien Android

5. Tampilan Menu Riwayat Pasien Android

Menu data riwayat pasien pada Gambar 20 berisikan semua informasi detail penyakit yang diderita pada pasien.

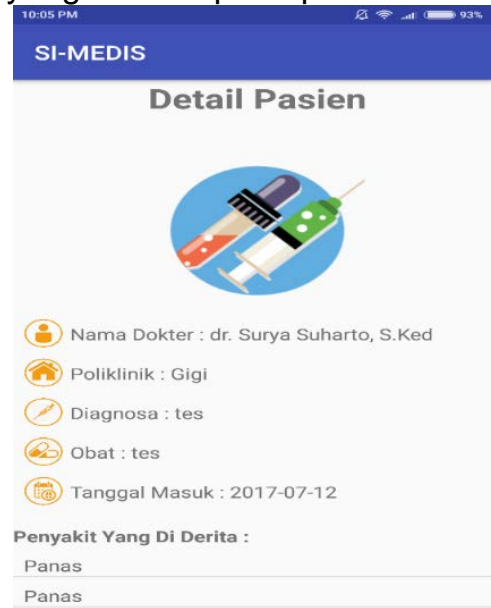

Gambar 20. Menu Riwayat Pasien Android

\subsubsection{Pengujian Aplikasi}

Pengujian aplikasi sistem informasi medis menggunakan barcode berbasis Android dan dekstop menggunakan metode black box yang dimana pada saat pengujian melibatkan beberapa fungsi telah berjalan dengan baik dan valid. Sehingga sesuai dengan tatacara pengujian black box [12].

\section{SIMPULAN DAN SARAN}

Aplikasi dirancang dalam dua aplikasi yang berbeda yaitu berbasis desktop dan Android yang disertai dengan database untuk menyimpan data, sehingga admin dan operator dapat melakukan pendataan dan pengambilan informasi pasien lebih cepat. Aplikasi smartphone berbasis Android ini juga dirancang dengan tujuan untuk dapat memudahkan pemberian informasi riwayat penyakit pasien kepada dokter. Pengujian aplikasi menggunakan metode black box testing yang berfungsi untuk menguji seluruh fungsionalitas dari aplikasi baik berbasis desktop maupun berbasis Android. Hasil pengujian yang diperoleh adalah seluruh fungsionalitas dari aplikasi berjalan dengan baik dan valid.

Untuk pengembangan lebih lanjut, aplikasi ini nantinya dibuat agar dapat dikembangkan dan dijalankan pada perangkat dengan sistem operasi lain, IOS atau Windows phone. Perlu juga pengembangan fitur pada Android agar dokter dapat mengirimkan informasi pasien setelah berobat pada admin atau operator. Hal ini memudahkan dalam penambahan data.

\section{DAFTAR PUSTAKA}

[1] Malik, Jaja Jamaludin. Implementasi Teknologi Barcode Dalam Dunia Bisnis,Andi, Yogyakarta. 2010

[2] Neobytesolutions. Desktop Applications vs. Web Applications. Retrieved June. 2012

[3] Syari'ati, F.M. Pengembangan Aplikasi Mobile Collabtive sebagai Project Management Collaborative Software pada Sistem Operasi Android, Program Studi S1 Ilmu Komputer, Jurusan IImu Komputer dan Elektronika, Fakultas MIPA, Universitas Gadjah Mada, Yogyakarta. 2012

[4] Parawanto, D. Sistem Informasi Administrasi Dan Pendaftaran Pasien Pada Rumah Sakit Ibu Dan Anak "Sadewa". Sekolah Tinggi Manajemen Informatika Dan Komputer, Amikom. Yogyakarta. 2012

[5] Jamal, A. dan Yulianto, L. Rancang Bangun Sistem Informasi Aplikasi Kasir Menggunakan Barcode Reader Pada Toko Dan Jasa Widodo 
Computer. Indonesian Jurnal on Computer Science Speed, Volume 10 No 4. Ngadirojo Kabupaten Pacitan. 2013

[6] Mariyam. Aplikasi Teknologi Barcode Untuk Menurunkan Kesalahan Dalam Pemberian Obat Dan Transfusi Darah. Universitas Indonesia. 2010.

[7] Tominanto. Card Elektrik (Barcode) Sebagai Sistem Komputerisasi Rekam Medis Di Rumah Sakit Medika Mulya Wonogiri. Jurnal IImiah Rekam Medis dan Informatika Kesehatan, VOL. 1 NO. 1. 2010

[8] Teguh Wahyono. Membuat Sendiri Aplikasi Memanfaatkan Barcode. Elex Media Komputindo. Indonesia. 2010

[9] Abdul Kadir. "Buku Pertama Belajar Pemrograman Java Untuk Pemula". Universitas Gadjah Mada. Yogyakarta

[10] Fathansyah. Basis Data, Informatika, Bandung. 2007

[11] Andri Kristanto. 2008. Perancangan Sistem Informasi Dan Aplikasinya. Penerbit Gaya Media Yogyakarta

[12] Mustaqbal . Pengujian Aplikasi Menggunakan Black Box Testing Boundary Value Analysis. Jurnal IImiah Teknologi Informasi Terapan, Volume I NO.3 2015 